\title{
A Reflection on Management Reform to Cultivation Process of Part-time Postgraduate in Local Agricultural Colleges
}

\author{
Zhiying Wang ${ }^{1}$, Minhua $\mathrm{Xu}^{2}$ \\ ${ }^{12}$ Jilin Agricultural University, Changchun 130118, china
}

Keywords: Colleges; agricultural, part-time postgraduate; cultivation quality

\begin{abstract}
Part-time postgraduate education in local agricultural colleges lacks of high-quality students' resources and meanwhile the cultivation quality is urgently to be improved. In addition, the lasting period of paper and experiment is very long with high labor intensity. The paper, directs at courses, proposal, mid-term examination, scientific research and test, thesis defense and other different cultivation stages of part-time agricultural postgraduates, emphasizes process management and constructs a high-quality cultivation system related to part-time agricultural postgraduate that is suitable for northern colleges.
\end{abstract}

\section{Introduction}

In order to achieve the balanced development between full-time and part-time postgraduate education and promote the standardized management for part-time postgraduate education, General Office of Ministry of Education issued Notice about Coordinating Management Work of Full-time and Part-time Postgraduates by General Office of Ministry of Education (thereinafter referred to as the Notice) on September 14th, 2016. The Notice clearly stipulates that postgraduates enrolled after December 1st, 2016 is divided into two categories: full-time postgraduates and part-time postgraduates. In other words, the Graduate Candidate Test (GCT) that has been adopted for many years was cancelled. The Notice still requires that full-time and part-time postgraduate education should follow the same quality standard so as to ensure equal quality education; In addition, the Notice clearly requires that postgraduate cultivation unit should strengthen management for cultivation process and construction for quality assurance system so as to guarantee the cultivation quality of part-time postgraduates. For agricultural colleges, especially local agricultural colleges located in inland economically backward area, they lack of hot disciplines and they are poor in faculties and backward in hardware conditions, which lead to inferior quality in sources of students. Therefore, the students are incapable in independent learning and innovation ability. Combining working experience and according to the features of local agricultural colleges, the author puts forward some reform measures to improve cultivation quality and management from the perspectives of postgraduates' management and cultivation and from the angle of perfecting students' self-restraining mechanism, so as to improve the cultivation quality of part-time postgraduates in agricultural colleges.

\section{Re-Formulating Cultivation Program, Further Optimize Course System}

Postgraduate cultivation program is the guideline document for daily cultivating postgraduates, the basic principle for formulating personal cultivating plan, the powerful guarantee for standardizing course settings, integrating teaching sources and strengthening process management, meanwhile the activity guides for teachers and students to conduct daily teaching activities. Therefore, the compilation of and revision to cultivation program directly affects quality for cultivating postgraduates and is the key factor to decide whether realize the overall objective of meeting talents requirements by local economic construction.

According to requirements in the Notice, it is necessary to "formulate cultivation program respectively" and "guarantee the equal cultivating quality between full-time postgraduates and part-time postgraduates education". Owing to the part-time postgraduates enrolled after the year 2017 are different from current full-time postgraduates and the past on-job postgraduates, the cultivation 
program for this batch of postgraduates should mainly observe the following principle: "emphasize innovation, improve quality", "take disciplines as the root, explore the frontiers", "set course on demand, sharing of resources", "creation of atmosphere and promotion of communications". Guided by the principle, formulation of cultivation program should take the following requirements into consideration:

(1)Research and discuss postgraduates' cultivation objectives in a deep manner, make clear of knowledge framework for postgraduates cultivation. Firstly, it is necessary to consider that part-time postgraduates have working experience, which needs to combine basic theory well with production practice. Secondly, it is necessary to show knowledge hierarchy at different course stages for bachelor, master and doctor.

(2)Course setting according to first-level discipline. Specialized core course should be designed from the first-level discipline while the settings for optional course should consider requirements of different disciplines.

(3)Absorb opinions and suggestions given by experts of key universities and colleges, working unit and graduates; strengthen communication, coordination and cooperation among different subjects.

(4)Courses determined in cultivation program should be supported with syllabus, including teaching objectives, course content, teaching requirements, credit and period, assessment method, references, etc.

\section{Main Problems Existed In the Management Process of Cultivating Part-Time Postgraduates}

Reform way of Teaching. In the past, one teacher is responsible for one subject, and two or three teachers are at most. After reforming the way of teaching, the most outstanding feature is that several teachers are sharing the same lessons for some professional basis and courses. The teachers are required to impart his academic essence to the students in a very short period. The biggest benefit is to compress school period substantially and the postgraduates can finish courses within one semester or a little more time. They can start field experiment at the second semester (spring season) in the first year at college. For northern colleges where harvest once in a year, there are totally two planting cycles during the three-year part-time postgraduate studies. So the results can be more authentic, avoiding academic misconduct to the maximum extent.

Another feature of reforming way of teaching is that: one subject finished in one semester is reformed to be finished in two or more semesters. Leave the time in spring (sowing seed), summer (field management), autumn (reaping) to students themselves for writing thesis and making experiments. The rest of time is used for learning theoretical courses. In addition, the part-time postgraduates majored in agricultural related disciplines will suffer more working pressuring in busy farming season. This type of teaching mode can relieve their working and learning pressure to the maximum degree.

Course Teaching Management and Assessment. Affected by many factors, course teaching for postgraduates are not as emphasized as teaching in bachelor stage, especially some experts' or administrative teachers' classes, they often suspend the class because of business trips, have meetings or other reasons. Now, several teachers assume one professional basic and courses commonly, which means that they can make coordination with each other to guarantee that the class is not to be suspended and therefore the period of class is guaranteed. On the other hand, with several teachers commonly responsible for one subject, the period distributed to each teacher is cut; under such circumstances, the teachers can impart his academic essence to the students, improving teaching quality substantially.

In light of method of assessment, it is strongly prohibit from adopting the past review paper in the final examination. For the public elementary courses, the proportion taken up by close-book examination result should not be lower than $80 \%$ while this figure of professional basic course and specialized course shall not be lower than $50 \%$ so as to avoid e-motional score to the largest degree. Meanwhile, the comprehensive performance should include two to three items of paper writing, homework, class discussion, experiment skills, collection and sorting of scientific and research 
information in addition to results of close-book examination so as to fully activate subjective initiative. The comprehensive results can better reflect students' master ability for courses and have direct relevancy with assessment of scholarship and assistantship.

Research Proposal. Academic dissertation and academic papers that are published in periodicals is an important indicator to evaluate postgraduates' cultivation quality and are directly related to obtaining degree on time. Research proposal is the study plan about scientific research and experimental thesis formulated under the direction of tutor on the basis of extensive reading literature and research, which is conducted before starting subject research and experimental thesis.

Research proposal is the "general design" for two thesis during postgraduate study process. Multiple years' of postgraduate management experience shows that the more information about research subject grasped by the postgraduates, the more accurate understanding about scientific frontier is, the more wide the view point is and the more comprehensive to consider scientific problems are. The high quality the research proposal is the more smooth the experimental thesis is. Generally, the research proposal of postgraduate is the essential condition for completing a high-quality postgraduate dissertation.

As the thesis proposal is one the basis materials for dissertation committee to review students' qualification for defense of dissertation, the postgraduates are required to finish thesis proposal at the mid-term of the third semester. The content of thesis proposal should cover such aspects as academic dissertation proposed title, research direction, research purpose and significance, research status overview, experimental scheme, anticipated goal, innovation point, scheduling, references. After the thesis proposal is finished, the postgraduates are required to read out the thesis proposal in the report meeting, which is commonly reviewed and judged by subject group member whether the topic selected conforms to cultivation requirements, accurate understanding about scientific frontier and feasibility of scientific research so as to avoid the blindness of scientific research thesis. The part-time postgraduates should finish the thesis proposal in high quality because they have working experience or scientific research experience previously. Considering this, the part-time postgraduates are required to additionally elaborate on two points. One is to have experimental difficulty or anticipated difficulty and elaborate corresponding resolutions; second point is to give reference for essay, level of proposed publication and time arrangement in order to facilitate management for assessment.

\section{Resolutions and Development Direction for Part-time Postgraduates Cultivation Process Management}

Process Management of Scientific Research Experiments. Postgraduates are an essential part of scientific research team in colleges and universities. On the other hand, scientific research plays a significant role to the quality education for postgraduates. Agricultural related disciplines are stricter with practical ability and production practice ability, which means that scientific research is not only completed in laboratory but also to be verified through long-term field experiments. Especially, the author's university, Jilin Agricultural University, is located in the northern China where crops are reaped once a year. In light of this special situation, we make the following requirements for postgraduates' scientific research:

Regulate Tutor and Management Personnel's Responsibility For Managing Postgraduates Scientific Research. Firstly, make clear of tutor's responsibility and regulate tutor in guiding postgraduates scientific research work, including normative education for experimental operation, training on using large instrument, field experiment design and management, statistical analysis of data, compilation of report and other guides to postgraduates from a comprehensive perspective. In order to guarantee that the tutor has sufficient energy to guide postgraduates, the number of students under the guide of each tutor is limited. In addition, strengthen subjects and management personnel's responsibility for managing postgraduate's scientific research through safety education on lab and assessment, installation of access control system in lab door to check students' attendances, filing of original records and other measures.

Improve Postgraduates' Ability In Practice Through Regulating Management For Sharing Scientific Research Resources. In order to enable students have more opportunities to contact various 
types of instruments and improve ability in practice, the college stipulates that special equipment purchased by research group should under its domination. The instrument and equipment purchased by school operation expense should be managed in two models. Using and maintenance for small processing equipment is assumed by research group while equipment with value exceeding 100,000 yuan should be managed by assigned person. Some equipment is only allowed to be operated under the guide of specially assigned person and the tutor should bear charges related to consumables and maintenance fees, but depending on the quantity of samples tested. Public room with special functions (sterility room, culture room, thermostatic chamber, etc.) should be under the management by specially assigned person for sharing use and improving utilization rate.

Improve Distribution System Of Scientific Research Results. The college has specific stipulations for the ranking and distribution of bonus for scientific research results with students participating in scientific research program, publication of thesis and authorization of patent, allowing postgraduates to participate in bonus distribution in order to stimulate their enthusiasm for scientific research. Considering that part-time postgraduates have their own working unit, the college has clear stipulations for scientific research results achieved in postgraduates' cultivation unit so as to avoid unnecessary property right disputes.

Encourage Postgraduates To Experience The First Agricultural Production Line Such As Scientific Research And Demonstration Bases. Learning from the "scientific yard" organized by Zihuan College of China Agricultural University and combining the feature that part-time postgraduates have rich practice experience, assign them to the experimental base where they board and lodge there for more than three months. The postgraduates can have a face-to-face contact with farmers there. While serving local farmers, the postgraduates can complete their own scientific research experiments and meanwhile improve self-quality from all around, laying a solid basis for work in the future.

Mid-Term Examination. Mid-term examination is a periodic assessment for postgraduates and also a process assessment. Combining assessment method for scholarship and fellowship, the college reforms mid-term examination system. From the aspect of assessed content, it is not the simple extension of scientific research after thesis proposal, but the comprehensive evaluation and assessment from the following four aspects: political thinking, course studying, phased results of thesis and experiment, publications of essays. The reasons to do so are listed as follows. Firstly, thesis proposal and academic dissertation can be combined in a good way and further find out and correct the shortcomings and errors in the thesis and experiments; secondly, linked with evaluation of scholarship and fellowship, it can stimulate students to make progress; thirdly, create a tense academic atmosphere for part-time postgraduates and urge them to carry out thesis and experiments smoothly, and therefore promoting to finish academic dissertation with a high quality.

Academic Dissertation. As the key link for improving postgraduates' cultivation quality, academic dissertation is an important way to test students' scientific research ability and studying achievements in college. All postgraduates should finish their own academic dissertation before graduation; only those who pass thesis defense can obtain degree. In order to improve the quality of academic dissertation, specific detailed assessment measures are made in each link of thesis proposal, scientific research process and mid-term assessment while strict rules are formulated for reviewing condition and process as well as thesis defense.

Evaluation for Scholarship, Fellowship and Other Awards. Since the autumn semester in 2014, China implements the system of charging fees toward postgraduates in an overall way. In order to encourage innovation and make more postgraduates devoted to studies and scientific research as well as provide long-term guarantee for quality cultivation education, the college issues scheme to reform postgraduate scholarship and fellowship system.

Tutor's Qualification Evaluation. For qualification certification and assessment basis for full-time postgraduate tutor, take tutor's scientific research project, scientific research results and expenditure and publication of academic paper into consideration. For qualification of part-time postgraduate, except for the above assessment indicator, production time also is a key factor. 


\section{Conclusion}

The above content is management regulation for part-time postgraduate education and measures to be adopted, which is more suitable for agricultural part-time postgraduates in northern China. But under the background of adapting to new situation, the education reform of improving postgraduates' quality is at the preliminary exploration stage, which means that various kinds of problems might be rose during implementation of measures. These problems can only be solved and improved through practice. Only in such a manner can part-time postgraduate education meet economic and social development requirements and achieve the overall objective of serving for local economic construction.

\section{Acknowledgements}

This work is "Study on management reform to cultivation process of agricultural college postgraduates under tuition-charging system", an education and scientific planning topic in Jilin Province (GH150223)

\section{References}

[1] Gao. Xuemei, Yu Xurong, Deng Changhui, etc. Research and Construction for Postgraduate Education Quality Assurance System in Local Agricultural Colleges [J]. Higher Agricultural Education, 2016, (5):82-86.

[2] Yuan Bentao, Huxuan, Yang Lili, Target And Route: An Analysis of Content of Cultivation Scheme for Professional Degree [J] Research in Higher Education of Engineering, 2015 (5):136-143.

[3] Zhangyi, Dingbiao, Zhangyang. Research in Postgraduate Dissertation Quality Process Management Indicator [J].continuing education, 2016, (7):70-72.

[4] Xia Lining, Guo Junxian, Zhao Hongqiong, etc. How to Cultivate Postgraduates with a Scientific Experimental Record Method [J]. Heilongjiang Animal Husbandry and Veterinary, 2015,(15):258-260.

[5] Wang Fubin; Chen Zhikun; Wang Yi. Quality Control and Practice for Guiding Process of Master Professional Degree [J].University Education, 2016, (10):59-60. 